\title{
COMPaCt STEP DOWn Voltage CONVERTER CONSTRUCTED IN TERMS OF EMC
}

\author{
Peter Janku, Martin Pospisilik \& Tomas Dulik \\ ${ }^{a}$ Faculty of applied informatics, Tomas Bata University in Zlin, \\ Nad Stranemi 4511, Zlin 760 05, Czech Republic
}
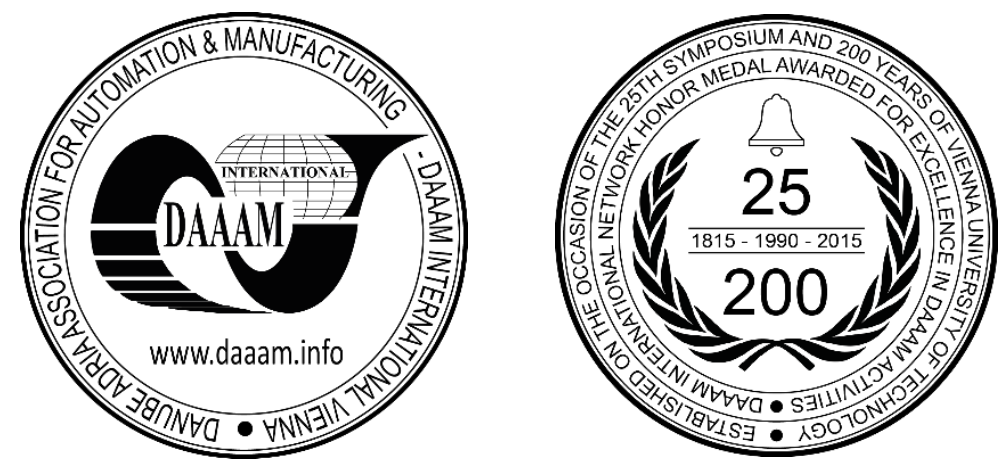

This Publication has to be referred as: Janku, P[eter]; Pospisilik, M[artin] \& Dulik, T[omas] (2016). Compact Step Down Voltage Converter Constructed in Terms of EMC, Proceedings of the 27th DAAAM International Symposium, pp.0514-0523, B. Katalinic (Ed.), Published by DAAAM International, ISBN 978-3-902734-08-2, ISSN 1726-9679, Vienna, Austria

DOI: $10.2507 / 27$ th.daaam.proceedings.077

\begin{abstract}
Designing of compact step down voltage converter must be provided according to the variety of standards and other requirements. Moreover, the constructed converter usually have to accomplish a set of opposite requirements defined by a target project or a target user (small size vs. high maximum level of provided current, etc.). Therefore the designing of converter could be really tricky. This paper tries to show the possibilities of a really low-end DC/DC converter based on controller AOZ 1284. Moreover, the constructed device is a subject for set of measurement. These measurements are performed in order to confirm that the device meet all requirements defined by standard EN 61000-6-3. All measurement results together with some necessary measures are presented at the end of this paper.
\end{abstract}

Keywords: EMC; step down converter; power supply.

\section{Introduction}

In modern electronic designs, the low price and compact size are two basic requirements defined by customers. At the other side, modern electronic devices have to meet really strict limitations defined in local or global EMC standards. These two opposite requirements, in common with wide variety of custom integrated drivers available on market, makes the correct step-down converters design really tricky.

This paper follows the previously based study [1] in which two different step down voltage converters were described. In following sections the step down converter based on AOZ1284 is discussed. The main advantage of this controller is its wide range of working frequency. Thanks to this, one of the most voluminous parts - inductor, can be chosen with relatively low value. The second, but not least advantage is its price - selected controller due to its parameter is one of the cheapest available on the market. [6,12]

The problematic of electromagnetic compatibility is wide discuss theme in scientific publication. Although that EMC can be divided into two separate parts: EMI - electromagnetic interferences and EMS - electromagnetic susceptibility, 
EMI is more problematic part for step-down converters. Measurement of radiated field and measurement of interferences on input wires are presented in this paper.[13]

The measurements of real parameters of step down controller are presented in this paper. Moreover, the main disadvantage of this converter - EMC interference level is discussed common with design of measures. All measurements and measures were performed to meet the requirements placed by working conditions and the standard EN 61000-6-3.[2$4,12]$

\section{Description of the tested converter}

The converter, which parameters and performance are discussed in this paper, was constructed according the specifications defined in section 2.1. These specifications were defined on a real embedded project requirements. In this project, new special secured access system will be developed in cooperation with specific company.

\subsection{Operating requirements}

As was told before, operating requirements were defined on real project base. Whole required electric characteristics are listed in Table 1. In addition, there were special requirement on size of whole DC/DC converter and finally the price had to be as low as possible.

\begin{tabular}{|c|c|c|}
\hline \multirow{2}{*}{ Parameter } & \multicolumn{2}{|c|}{ Value } \\
\cline { 2 - 3 } & Min. & Max. \\
\hline Input voltage & $12 \mathrm{~V}$ & $24 \mathrm{~V}$ \\
\hline Output voltage & $5 \mathrm{~V}$ & $5 \mathrm{~V}$ \\
\hline Output current - continuous & $150 \mathrm{~mA}$ & $300 \mathrm{~mA}$ \\
\hline Output current - peak & $500 \mathrm{~mA}$ & $800 \mathrm{~mA}$ \\
\hline Power efficiency & $80 \%$ & - \\
\hline
\end{tabular}

Table 1. Electrical operating requirements

\subsection{Converter circuit description}

The converter, which parameters and performance are discussed, is based on AOZ1284 controller. The whole design was performed with respect to the manufacturer's notes provided within the datasheet of the circuit [5]. The circuit diagram of this converter is depicted in Fig.1.

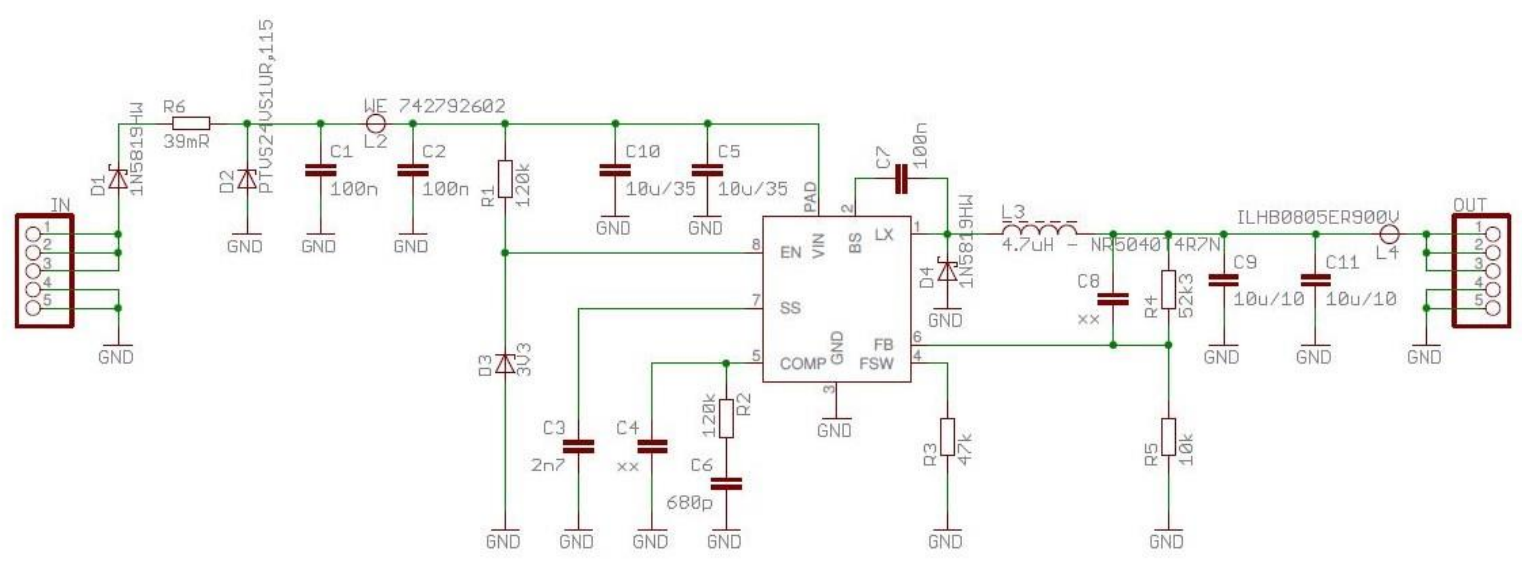

Fig. 1. Circuit diagram of a voltage converter based on AOZ 1284

As could be recognized from provided schematic, the switching transistor is integrated on the chip. The circuit operation is based on Continuous-Conduction Mode (CCM) in fixed frequency.

The inbuilt transistor is N-MOSFET switch. The inductor current is sensed by amplifying the voltage drop across the drain to source of this MOSFET. Output voltage is divided down by external voltage divider (defined by R5 and R4), it's internally compared with internal reference voltage source and amplified by the internal transconductance error amplifier. The error voltage is compared against the current signal, which is sum of inductor current signal and ramp compensation signal, at PWM input. If the current signal is less than the error voltage, the internal high-side switch is on. The inductor current flows from the input through the inductor to the output. When the current signal exceeds the error voltage, the high-side switch is off. The inductor current is freewheeling through the Schottky diode to output.[5,6] 
As it is described above, the whole converter works on a fixed frequency defined by the internal oscillator. It can be programmed by external resistor connected to the FSW pin. In this specific circuit the operating frequency is set by R3 to value $961 \mathrm{kHz}$.

The circuit is equipped with filters (C1, L2 and C2) and with set of two protective diodes. The D1 take care about right input voltage polarization and the D2 works as overvoltage protection. Moreover, there is a Zener diode connected to the enable pin of converter, which is able to disable converter, when the input voltage is under the limit defined by manufacturer. $[4,6,10,11]$

\section{Measurements and results}

The described circuit was constructed as a functional sample and tested for achieving of the required parameters. Consequently a set of test was performed in order to gain data set needed for implementation of the DC converter into the final product. As in the previous research and in context of the requirements, the standard EN 61000-6-3 had been chosen, since the target use of the circuits was not specified.

The tests were as follows:

- output voltage stability versus output load,

- power efficiency at different output load and input voltages,

- maximum output power according to the cooling capability of the components,

- electromagnetic interference without a cover according to EN 61000-6-3,

- interference currents on the input cables measured by a current clamp according to EN 61 000-6-3.

\subsection{Measurement configurations}

Three basic measurement network configurations were used in order to obtain the above described data:

- measurement of DC static parameters,

- measurement of radiated electromagnetic field,

- measurement of interferences on input cables.

\subsubsection{Measurement configurations}

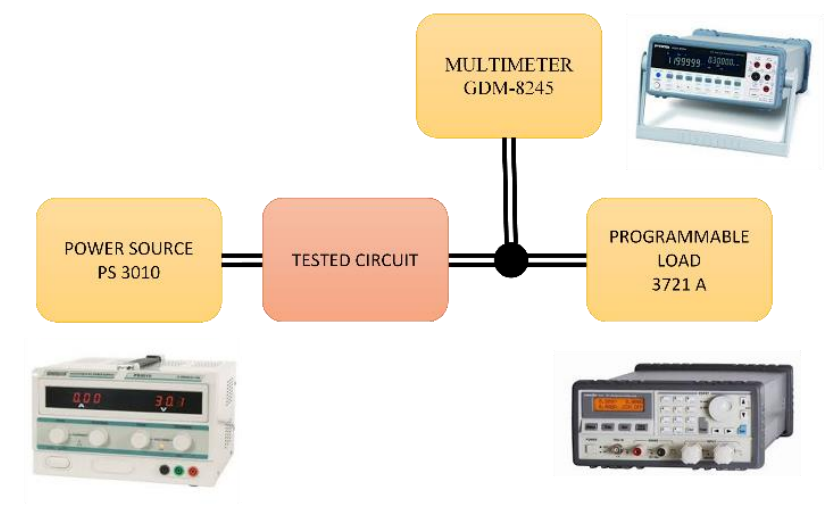

Fig. 2. Configuration of measurement network for validating of converters static DC parameters. [1]

The DC parameters were measured by using stabilized laboratory power source Velleman PS3010 as converters voltage input. The converter output was stretched by programmable electronic load Array 3721A operating in constant current mode. The input voltage and current were measured by set of two RMS multimeters. The output parameters voltage and current were measured directly by the electronic load. Its accuracy was randomly checked with another RMS multimeter.

\subsubsection{Radiated electromagnetic field}

The intensity of electromagnetic interference was measured in a semi anechoic chamber in order to avoid other signals ordinary presented in environment. The measurement network is visualised in Figure 3. As can be seen, it is composed of a bilogarthmical antenna Teseq Bilog CBL 6112 connected to the Rohdel\&Schwartz ESU 8 test receiver and spectral analyser. The measured controller was loaded by the electronic load Array 371A, that sunk a current of $0.2 \mathrm{~A}$ and as power 
supply the lead battery was used. The potential interferences caused by the electronic load were excluded by additional measurement during which the converter was bypassed. All obtained data were collected and processed by means of EMC 32 software. [7-9]

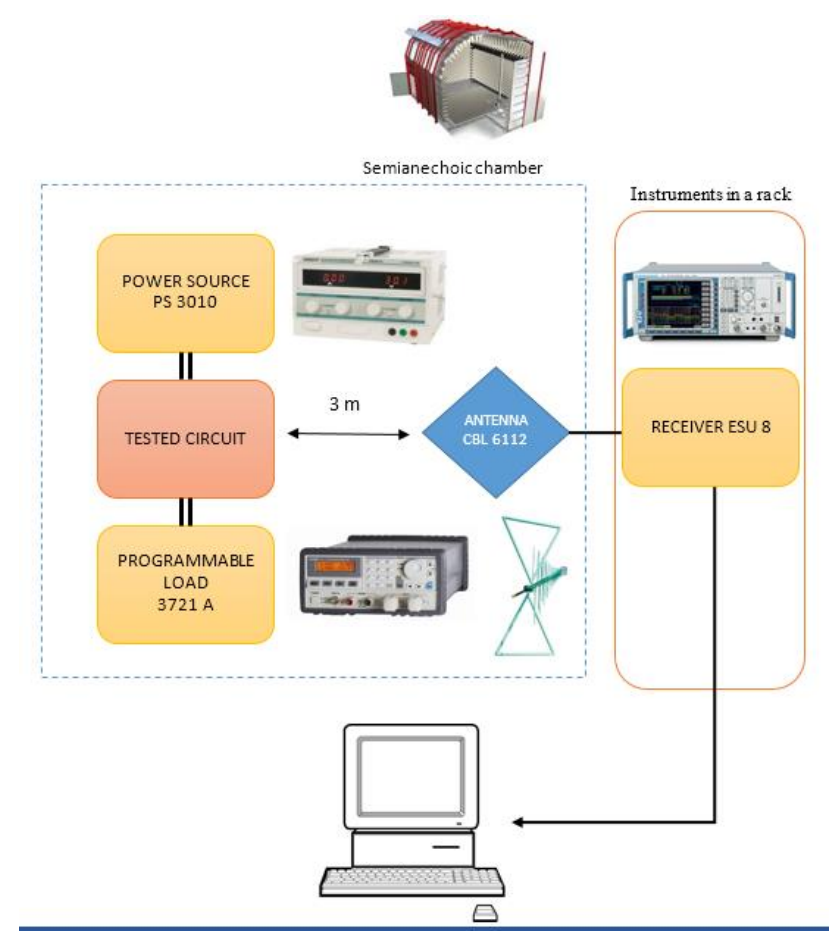

Fig. 3. Configuration of the experiment consisting in measurement of electromagnetic field radiated by the tested voltage converters. [1]

\subsubsection{Interferences on input cables}

The third measurement configuration was built in two stages. In the first one the current probe F-52 was used as the sensor connected to the ESU 8 receiver. This configuration was used in previous research [1]. In the second stage, the current probe was replaced by a LISN Rohdel\&Schwarz ENV216 which can meet the requirements of CISPR 16-1-2, EN 55016-1-2. Both stages were compared with positive results - the same values were gained by both sensors. Therefore the second stage measurement network was selected as the one used for whole measuring of interferences on input cables.

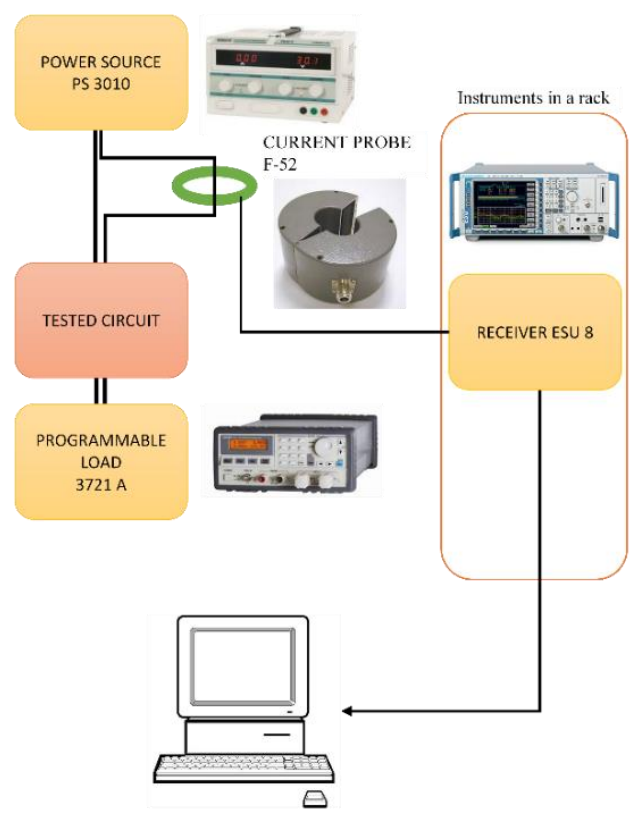

Fig. 4. Configuration of measurement network used for measure on input wires by using current probe. [1] 
The obtained data were collected in EMC 32 software and post processed in MS Excel. Tested circuit was powered by laboratory power source PS3010 and the output current was consumed by programmable load Array 3721A. Final experiment configuration is described in picture Fig. 4.

\subsection{Obtained results}

By using measurement networks and devices described in previous parts of this paper, a large set of results was obtained. The most interesting and important results are presented in this section.

\subsubsection{DC parameters}

The first measurement was performed in order to verify required parameters of constructed converter. After static verification of output voltage, the load characteristic was measured. As can be seen in Fig. 5, the output voltage naturally goes down together with rising output current load. Moreover, significant output voltage drop down was measured on 24 $\mathrm{V}$ input and $400 \mathrm{~mA}$ output current. Despite this fact, maximal voltage drop down achieved $44 \mathrm{mV}$ (in case of $15 \mathrm{~V}$ input), which is absolutely acceptable level.

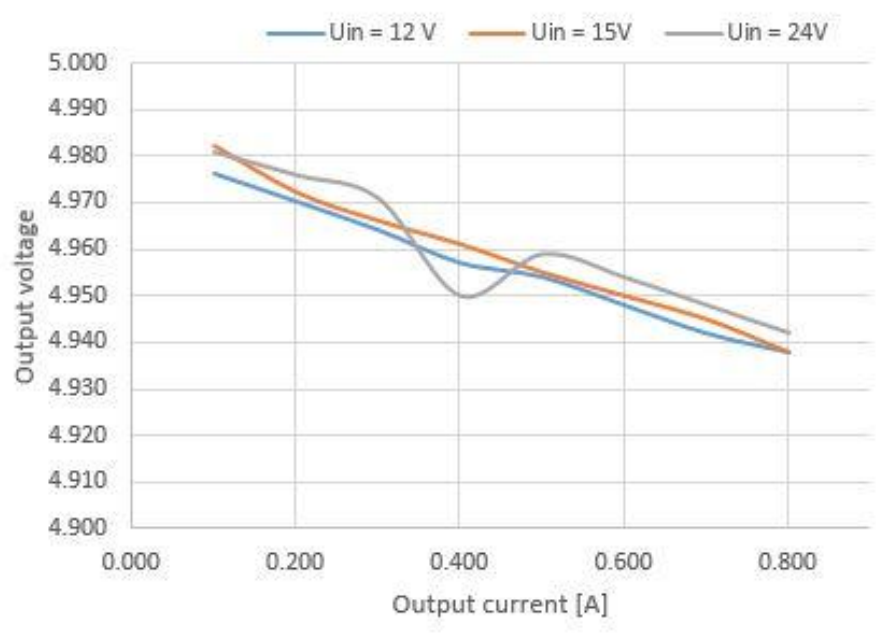

Fig. 5. Output voltage dependence on the output current and input voltage

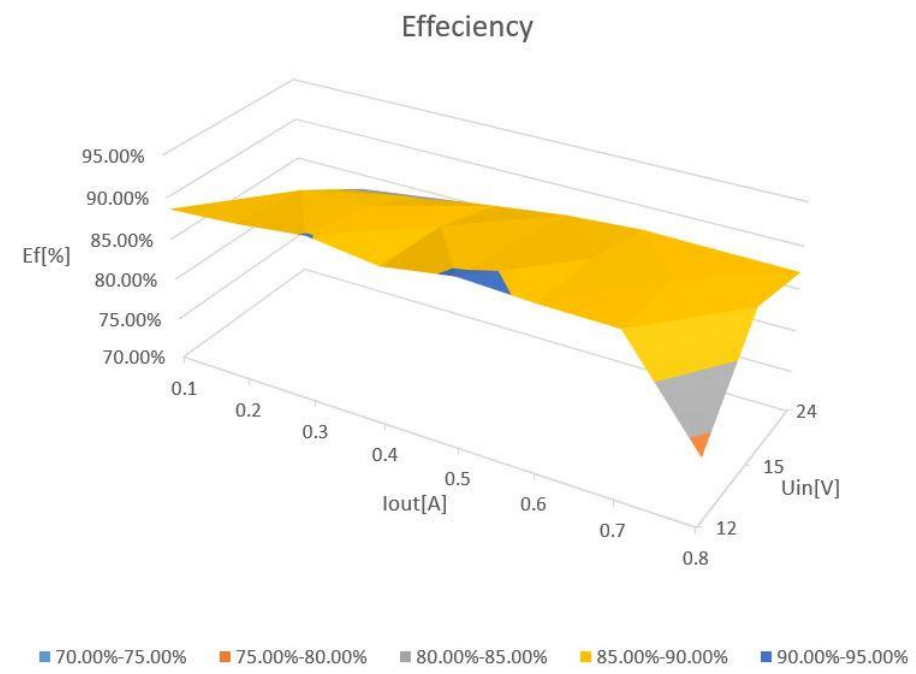

Fig. 6. The converter efficiency in different working conditions

The converter's power efficiency was calculated from the measured input and output power. It is depicted by Fig. 6 . As can be noticed, the average value of power efficiency is about $87 \backslash \%$. The highest value was measured at the input level of 12 voltage and the output current of $500 \mathrm{~mA}(90.331 \%)$. At the other side, the lowest efficiency was observed at the input level of 12 voltage and the output current of $800 \mathrm{~mA}$ and at the input leve of 24 voltage and the output voltage of $100 \mathrm{~mA}$. 


\subsubsection{Electromagnetic interferences}

As it was described in previous sections, the electromagnetic interferences were measured according to the requirements of the standard EN 61000-6-3. The base band defined by this standard was from $30 \mathrm{MHz}$ to $1 \mathrm{GHz}$ and the measurement was performed on working prototype without any box or another shielding.

The converter mostly passed the test with small exceptions. In the Fig. 8 the worst test case result is shown. As can be seen, the only one problem is at the frequency of about $40 \mathrm{MHz}$, where the measured level exceed the limit over 1 $\mathrm{dBuV} / \mathrm{m}$. Nonetheless, the converter is expected to pass the test in real device with proper case.

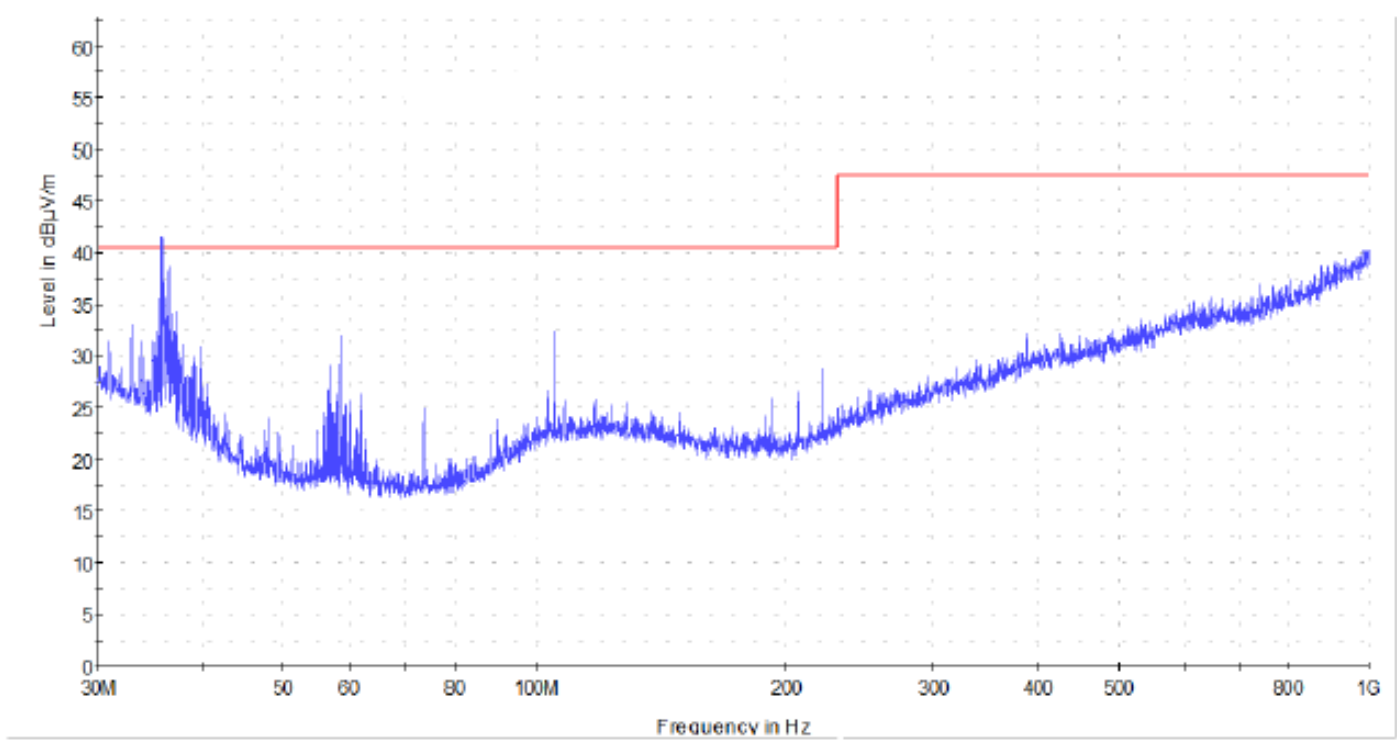

Fig. 7. The electromagnetic interference spectrum

It has to be mentioned, that together with measured sample, there were other devices in chamber (power source and programmable load. Theoretically, these two devices could produce some level of electromagnetic interferences. For this reason, the power source was replaced by a leaded battery. Moreover, the initial measurement was performed with bypassed converter in order to gain electromagnetic background in chamber. Because of significantly low level of electromagnetic interferences in chamber with bypassed converter, it could be claimed, that the measurement is correct and results are suitable.

\subsubsection{Interferences on input wires}

According to the principle of operation of the converters the current ripples and/or voltage peaks are expected to occur at its input and output cables. Within the framework of the standard EN 61000-6-3, a large set of measurements is expected to be processed. Due to limited size of this paper, only data gained on positive power supply wire are discussed here. The measurement configuration was described in previous section. In additional, as was described, the measurement was performed with ENV 2016 LSN network and verified by using a current probe. Both results were the same; therefore, only data measured by ENV 216 LSN are presented.

In the Fig. 8 and Fig. 9 the dependency of the measured voltage peaks spectrums on the output current (at a constant input voltage) is shown. It could be noticed from these pictures, that there are peaks starting from working frequency (about $961 \mathrm{kHz}$ ) and continuing on its harmonic frequencies up to $30 \mathrm{MHz}$. Moreover, most of these peaks break the limits defined by the standard. The most visible exceeded is noticeable at 24 voltage input and low output current. In this stage, the converter is working in a discontinuous mode and it is producing highest level of interferences.

Based on previous findings, it can be expected, that this converter will not pass the standard requiremetns of interferences on the input wires anymore. Therefore, a new input LC (inductor - capacitor) filter has been designed, built and, in the form of a functional sample, connected to the voltage convertor. After that all previous measurements on input wires were repeated.

The second set of input ripple voltage spectrum measurements (after the filter was applied) is shown in pictures Fig. 10 and Fig. 11. It is clear, that the measured results are significantly better after the filter application then before. The whole spectrum is lowered down; especially the peaks on working frequency and another harmonics frequencies. In this consequence, it could be expected that the designed voltage converter with appropriate input filter will be able to pass the tests defined standard EN 61000-6-3. 


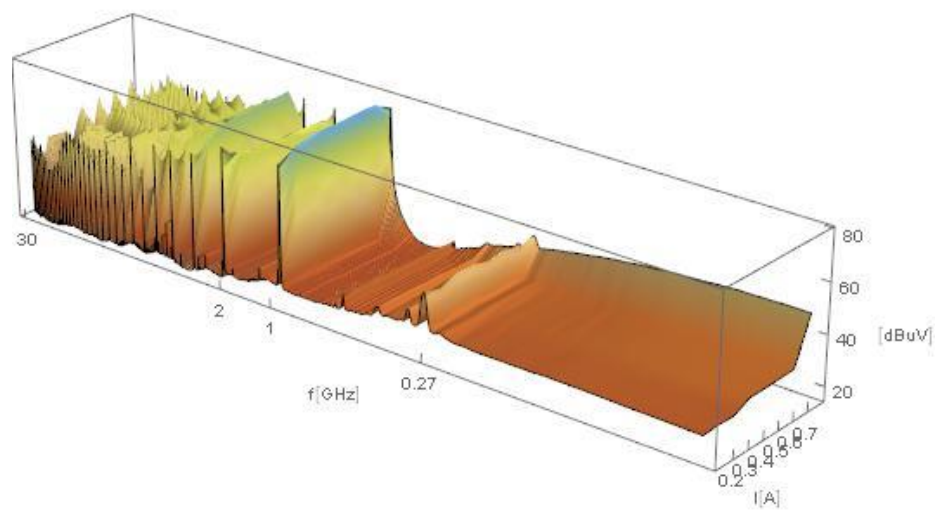

Fig. 8. Ripple current spectrum on the input wire (constant input voltage 12V), no filter applied

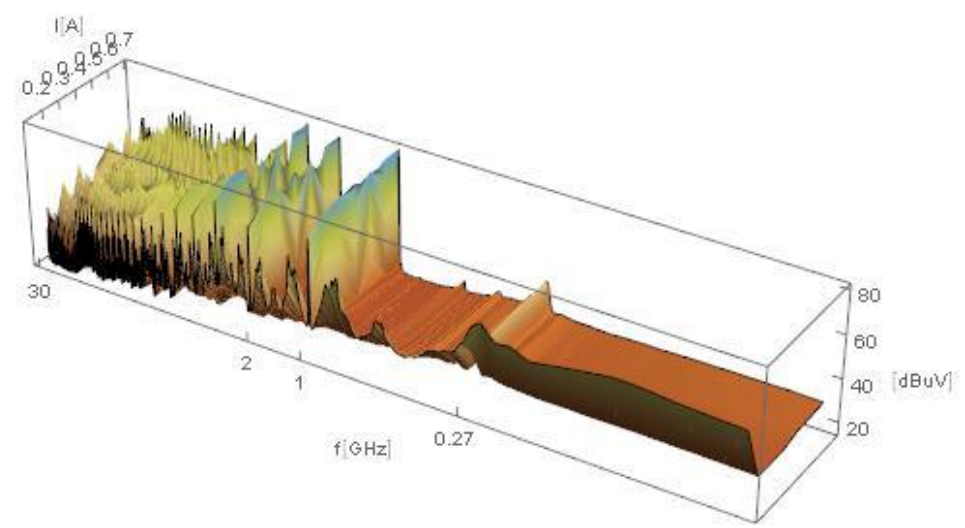

Fig. 9. Ripple current spectrum on the input wire (constant input voltage 24V), no filter applied

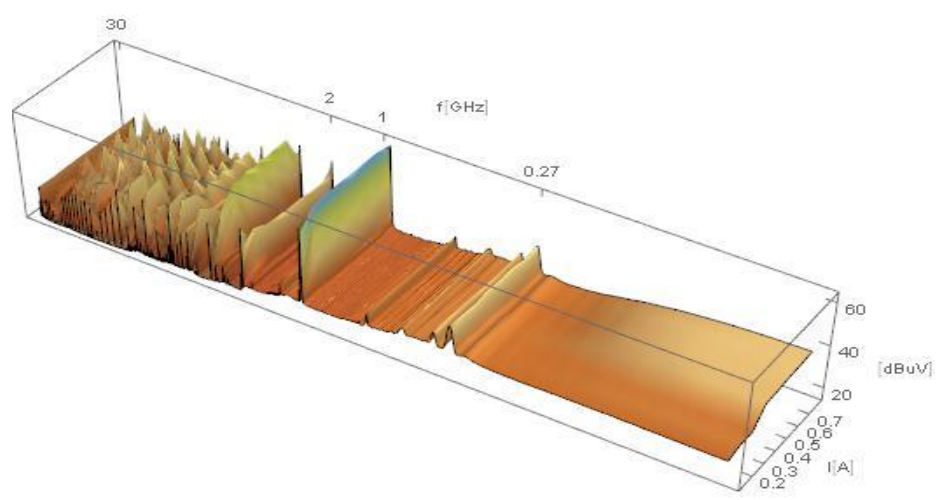

Fig. 10. Ripple current spectrum on the input wire (constant input voltage 12V), designed filter connected

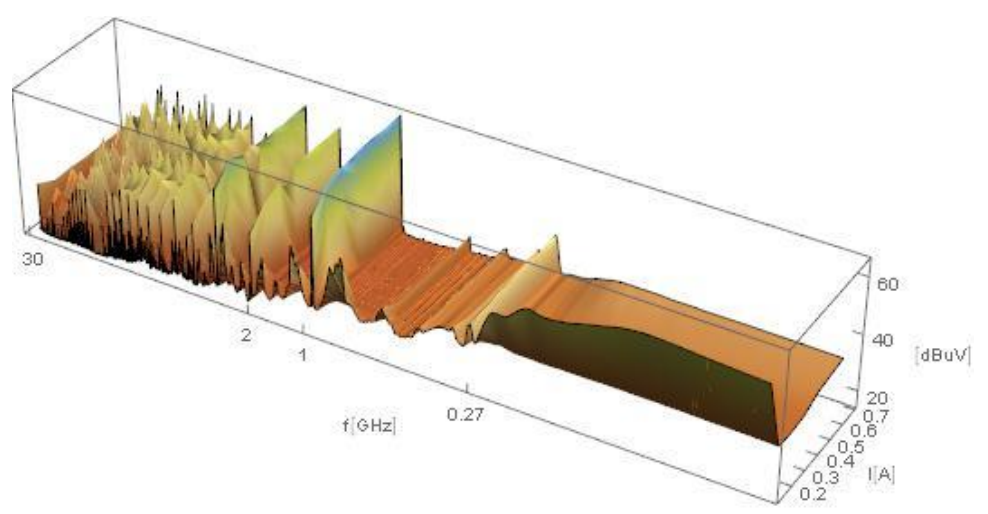

Fig. 11. Ripple current spectrum on the input wire (constant input voltage 24V), designed filter connected 
The most significant improvement can be seen if we made a comparison two ripple current spectrums measured at one output current level. As can be found in Fig. 12 and Fig. 13 the improvement gained by the instalation of filter enormous. Moreover, It does not matter if the spectrum contains only peak (Fig. 14 - continuous mode) and/or if the spectrum contains wide range of frequencies (Fig. 15 - discontinuous mode). In both cases the filter is able to reduce maximal measured levels.

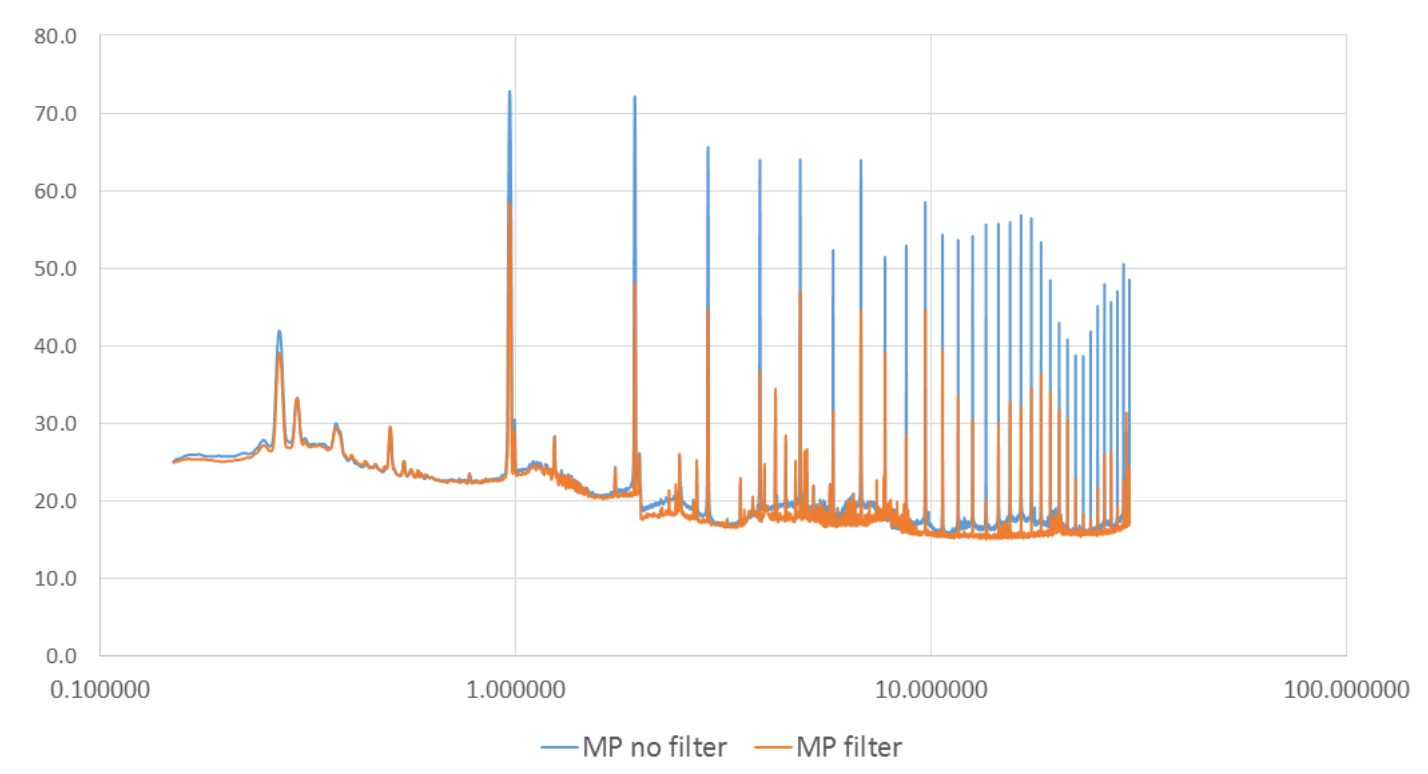

Fig. 12. Comparison of ripple current spectrum on the input wire (constant input voltage $12 \mathrm{~V}$ and output current $100 \mathrm{~mA}$ )

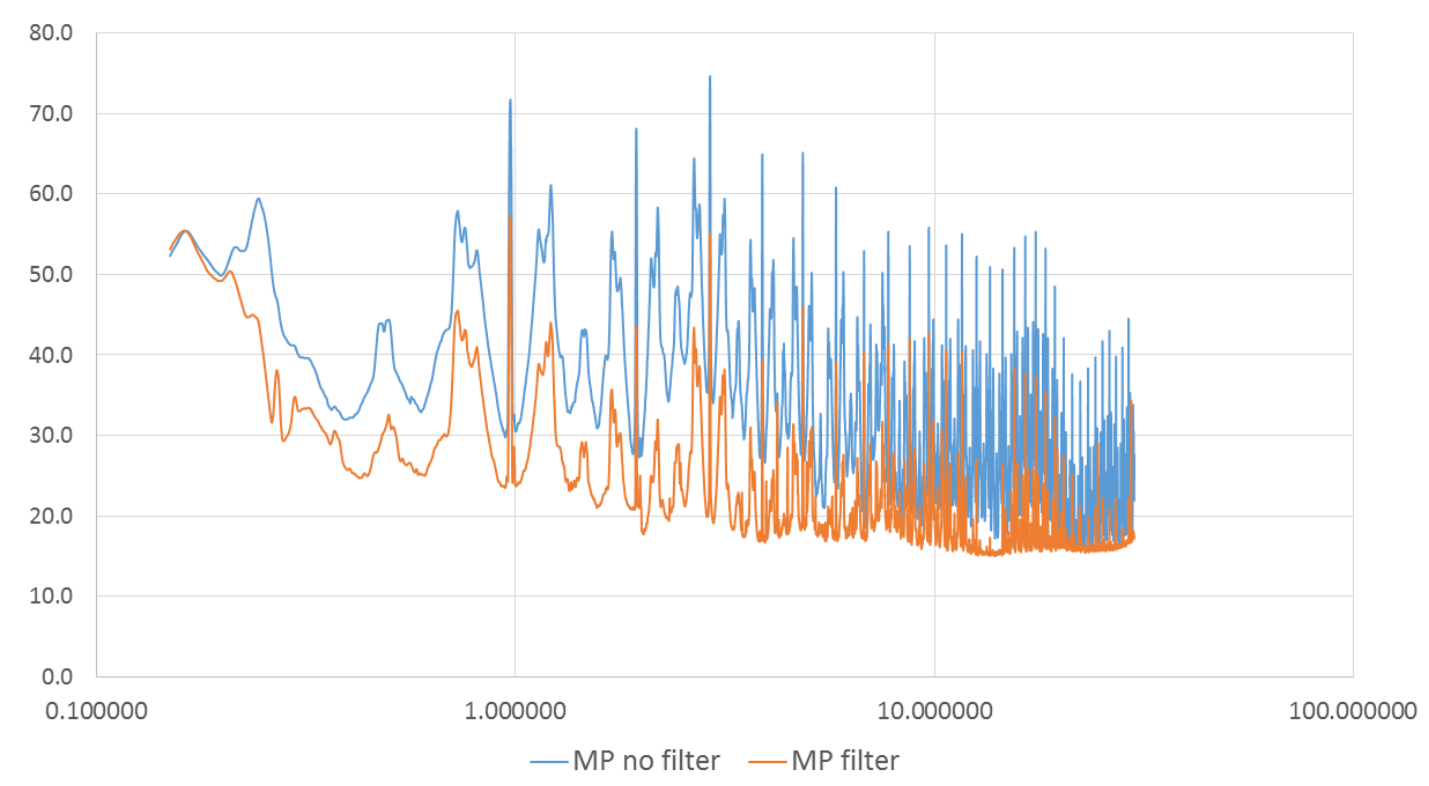

Fig. 13. Comparison of ripple current spectrum on the input wire (constant input voltage 24V and output current $100 \mathrm{~mA})$

All previous measurements were performed by using MaxPeak detector. It means, that the maximum level, which was achieved in spectrum subrange, was taken as a result. But the standard define the second possible detector called QuasiPeak. This detector does not take only one maximum value in subrange, but tries to weigh signals according to their rate in measured subrange. The result obtained by using QuasiPeak detector can be seen in Fig. 14, Fig. 15, Fig. 16 and Fig. 17.

As is shown in these figures, the situation is similar to previous measurement - the use of a proper filters allows meet the defined levels of the standards 


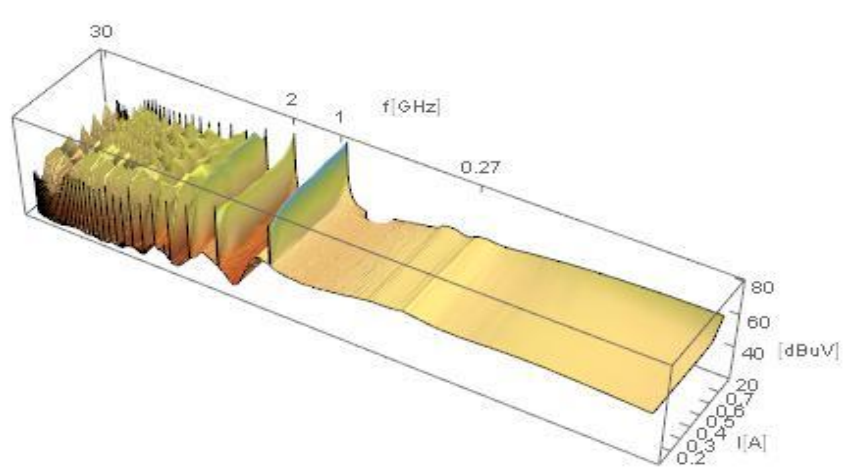

Fig. 14. Ripple current spectrum on the input wire (constant input voltage 12V), no filter applied. QuasiPeak detector used

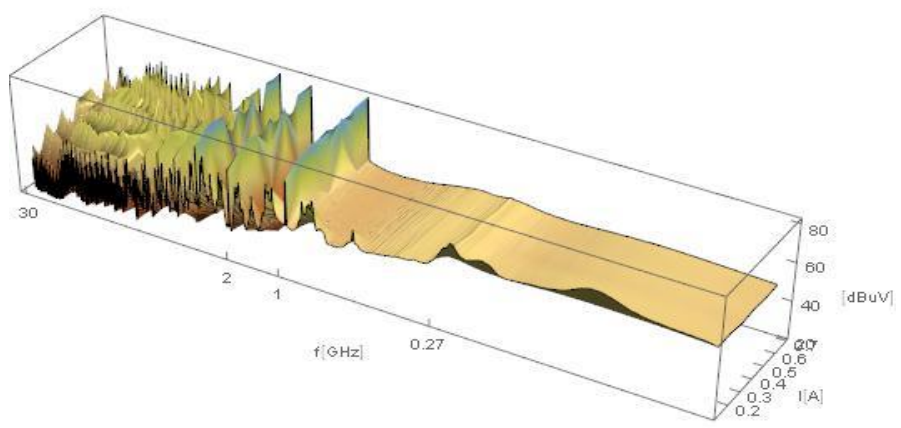

Fig. 15. Ripple current spectrum on the input wire (constant input voltage 24V), no filter applied. QuasiPeak detector used

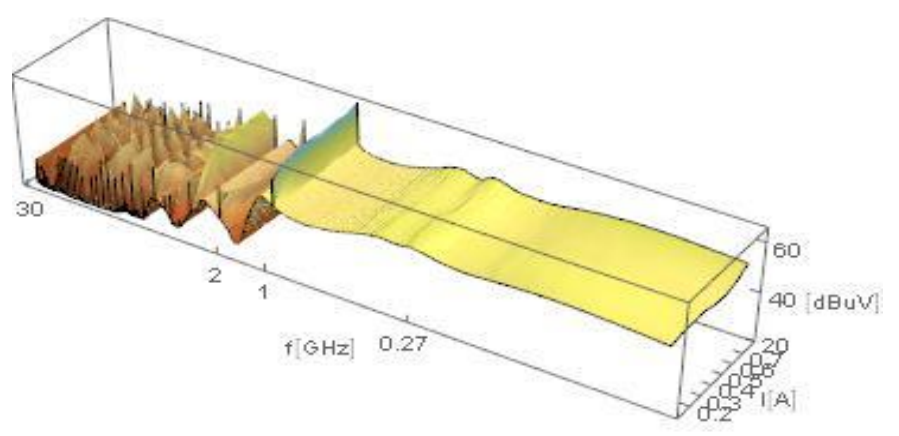

Fig. 16. Ripple current spectrum on the input wire (constant input voltage 12V), designed filter connected. QuasiPeak detector used

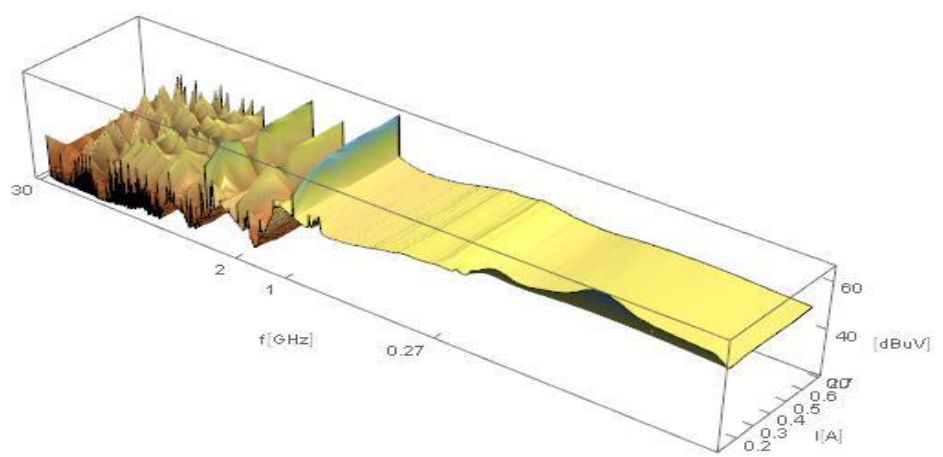

Fig. 17. Ripple current spectrum on the input wire (constant input voltage 24V), designed filter connected. QuasiPeak detector used 


\section{Conclusion}

This paper provides an overview about designing of a small cheap voltage converter, which can be useful for implementation into small embedded devices. As the basic driver, the small and simple controller the AOZ 1284 has been chosen. Based on the datasheets and manufacturers' recommendations, the DC/DC converter circuit was designed and the applicable sample was constructed. After that the static DC characteristics were verified, the set of control measurement of interferences was performed according to the requirements of the standard EN 61000-6-3.

The static DC measurements agree that all requirements defined in the start of this paper were fulfilled. The radiated electromagnetic field measurements shown, that the designed circuit is likely to meet the requirements defined by the standard. At the other hand, the measurement of interferences on input cables revealed a significant problem with the level of these interferences.

According to this information, the simple LC filter was designed and all necessary measurements were repeated. After the application of the filter, the level of interferences has been lowered.

Because of the level of the interferences produced by this converter also depends on the connected load and the PCB design, we did not continued in tuning of the input filter and converter into details.

According to the data we obtained it can be claimed, that the designed converter will be suitable for its designation; moreover, it can be expected, that it will be able to pass all requirements defined in standard EN61000-6-3 after small tuning of its parts. Together with the price of this converter (about 0.4 USD) and final size of whole design ( $2 \mathrm{~cm} \times 3$ $\mathrm{cm}$ ), this converter can be used as a replacement for frequently used MC34063 drivers and it could be sufficient competition for products of other manufacturers.

We would like to focus on other comparable integrated controllers of step-down converters in further research. Its real features and real measurements on test samples instead of simulations haven't been published well. Moreover, the input power filters and their impact on interferences on input wires will be interesting theme for further research.

\section{Acknowledgement}

This paper is supported by the Ministry of Education, Youth and Sports of the Czech Republic within the National Sustainability Programme project No. LO1303 (MSMT-7778/2014) and also by the European Regional Development Fund under the project CEBIA-Tech No. CZ.1.05/2.1.00/03.0089 and the Internal Grant Agency at TBU in Zlin, Project No. IGA/FAI/2016/036.

\section{References}

[1] M. Pospisilik, M. Adamek, R. M. S. Silva, Diferent constructions of step down voltage converters in termsof EMC, International Journal of Circuits, Systems and Signal Processing, Volume 10, (2016), p. 190-199, ISSN: 1998-4464

[2] J. Svacina, Electromagnetic Compatibility [Elektromagneticka kompatibilita], Brno: VUT Brno, (2002)

[3] C. R. Paul, Introduction to Electromagnetic Compatibility, New York: John Wiley, (1992)

[4] P. A. Chatterton, M. A. Houlden, EMC Electromagnetic Theory to Practical Design, New York: John Wiley, (1991).

[5] ALPHA \& OMEGA Semicondutor (2012, March), AOZ1284 Datasheet[online]. Available: http://aosmd.com/res/data_sheets/AOZ1284PI.pdf

[6] M. Pospisilik., T. Dulik, International Journal of Circuits, Systems and Signal Processing, Volume 8, (2014), pp 518 $-528$

[7] M. Mann, B. Gutheil, J. Zastrau, P. Weiss, Electromagnetic_eld measurements Means of veri_cation, In Proc. of the 5th WSEAS/IASME Int. Conf. on Electric Power Systems, High Voltages, Electric Machines, Tenerife, Spain, December 16-18, (2005), pp 591-595

[8] M. Pospisilik, J. Soldan, M. Adamek, Inuence of the Properties of a Real Semi Anechoic Chamber on an Internal Electromagnetic Field Distribution, WSEAS Transactions on Systems, Volume 14, (2015), pp 174 186, EISSN: 2224-2678

[9] J. A. Cartrysse, Measuring method for the characterization of shielding gaskets, in $8^{\text {th }}$ International Conference on Electromagnetic Compatibility, pp 251 253, Heriot-Watt University, Edinburgh, UK, September (1992)

[10] Z. Trnka, Theory of Electrical Engineering [Teoretick elektrotechnika]. Bratislava: SNTL Alfa, (1972)

[11] V. Kus, E_ects of Converters with Semiconductors to the Power System [Vliv polovodiovch menicu na napjec soustavu], Prague: BEN-Technicka literature, (2002), ISBN: 80-730- 0062-8

[12] Shah, R[ima]; Park, H[ong-Seok] \& Lee, G[yu] B[ong] (2016). Design For Assembly: An approach to increase Design Efficiency of Electronics Home Appliance, Proceedings of the 26th DAAAM International Symposium, pp.0877-0882, B. Katalinic (Ed.), Published by DAAAM International, ISBN 978-3-902734-07-5, ISSN 1726-9679, Vienna, AustriaDOI: 10.2507/26th.daaam.proceedings.122

[13] Ismaeel, J.M., Jayanthy, T., Sugadev, M., Kumar, M.A., 2008. Analysis of electromagnetic interface filters for power systems and telephone lines, in: 10th International Conference on Electromagnetic Interference Compatibility, 2008. INCEMIC 2008. Presented at the 10th International Conference on Electromagnetic Interference Compatibility, 2008. INCEMIC 2008, pp. 433-437 